\title{
Antecedents Factors Affecting Alignment and Its Impact to Organizational Performance in Universities
}

\author{
Juhana Salim \\ Centre for Artificial Intelligence \& Technology \\ Faculty of Information Science and Technology \\ Selangor, Malaysia \\ js@.ftsm.ukm.my
}

\author{
Esmadi Abu Abu Seman \\ Centre for Software Technology and Management \\ Faculty of Information Science and Technology \\ Selangor, Malaysia \\ esmadi.abu.seman@.gmail.com
}

Received: February 10, 2019. Revised: April 13, 2021. Accepted: October 10, 2021. Published: November 16, 2021.

\begin{abstract}
Business and Information Technology (IT) alignment involves applying IT in an appropriate and timely way, in harmony with business strategies, goals and needs. Prior research argues that achieving alignment contributes immensely to ensuring that IT investments improve organisational performance. One important issue in business-IT alignment study is the absence of alignment. Findings indicate that there are many factors/variables that consistently enhance businessIT alignment. By identifying factors to achieve business-IT alignment, the problem on the absence of alignment could be addressed. Due to the complexity of business-IT alignment, there is possibility that successful alignment focuses on managing specific alignment dimension by investigating factors that encourage particular dimension. Past studies have shown the relationship between business-IT alignment and organizational performance. However, only few researchers tried to relate between the factors with organizational performance. Literature on alignment discovered that there seems to be confusion in clarifying the business-IT alignment concept. Based on this gap, this paper examines problem and issues on alignment, identify, analyze and discuss factors affecting alignment, then categorize the constructs identified into dimensions and propose a model for alignment in universities. The study contributes to the formation of a theoretical model influencing alignment dimension that has impact on organizational performance. The model is important to provide empirical evidence that confirms the importance of categorizing factors into dimensions in achieving business-IT alignment and their influence on universities' performance.
\end{abstract}

Keywords-alignment, business-IT alignment, strategic planning, alignment model, IT strategy.

\section{INTRODUCTION}

In today's competitive business environment, the effective and innovative use of Information and communication technology may have enormous implications for the operation, structure and strategy of organizations. On the other hand poorly managed IT investment and badly implemented IT projects can cause value erosion and competitive disadvantage [56-57]. A number of organizational and company level studies and analysis show how IT contribute substantially to company's productivity and this contribution is strong where IT strategy is linked with business strategy [55]. Business-IT alignment is defined as a stage where the mission, objective, and planning within business strategy is shared and supported by IT strategy. This definition is extended to cover the situation where business executive and IT executive comprehended and are committed towards achieving the mission, objective, and plan for both business and IT. Business-IT alignment (hereafter called alignment) has been identified to permit IT investment to enhance organizational performance. However, organizations seem to find it difficult or impossible to harness the power of IT for their own long-term benefit, even though there is worldwide evidence [1-5]. Among the reasons for failure to generate return from IT investment is the absence of businessIT alignment in organization. According to Oana [6], the main reason for the absence of alignment is the lack of understanding on the concept of alignment. Oana [6] also explained that the absence of alignment causes the loss of opportunity and competitive advantage, waste of time, and cost increment, hence creating an environment that is negative to IT investment. Nevertheless, alignment has continued to be the key concern for both IT and business managers and has continued to garner attention despite decades of research. Earlier researches claimed that by aligning IS with business strategies and objectives, organizational benefits will accrue [7] and there were evidences that supported such assertion [8], [4], [9], [10], [1-2] and [11-15]. Chan et al. [16] demonstrated that strategic alignment is the main influence on organizational performance. On the other hand, Tallon and Kramer [17] argued that such a relationship is valid up to a certain point but beyond this threshold, further increases in alignment may yield lower payoffs. These conflicting research findings demonstrated that there is the need to get a better understanding of the dynamics of alignment.

This paper discusses part of a research undertaking on alignment in public universities in Malaysia. Prior studies on alignment discovered that there seems to be confusion in clarifying the business-IT alignment concept. Based on this gap, the aim of this paper is firstly to identify and analyze factors affecting alignment, then categorize the constructs identified into dimensions and propose a model for alignment in universities. The rest of the paper is organized as follows. Section 2 discusses the problem, issues and research gap in more detail followed by section 3 , the literature review that focuses on business-IT alignment models and antecedent factors which influenced alignment and alignment in higher institution of learning. Based on the argument discovered in the literature review in relation to dimensions and factors affecting alignment, section 4 explains the categorization of factors 
affecting alignment. Section 5 describes the research model advocated. Section 6 presents our conclusion.

\section{PROBLEM STATEMENT}

In the past decade, research on alignment further developed theoretical model on performance impacts of alignment and antecedent factors influencing alignment. However, factors affecting alignment received relatively little empirical attention and there has been little theory-based empirical research on the relative importance of the factors affecting it. Sabherwal and Chan [18] focused on alignment implications for firm performance but did not examine antecedents of alignment. Several empirical studies [19-23] that examined possible antecedents of alignment have reported diverse and sometimes conflicting findings regarding antecedents to alignment. Though [24] more recent research provides insights regarding antecedents to alignment, studying the influence of the dynamic interaction of antecedent factors that addresses processes that serve as antecedents to alignment would provide more valuable insights. They argued the relationships among these processes such as the processes that leads to shared knowledge and factors have been found strong and merit in depth examination.

Several studies on business-IT alignment [10] and [25-27] concentrated on development of new model or extended the existing model, stretching the alignment concept across many dimensions. An analysis on their findings showed that business-IT alignment concept definition was based on many categories of construct which are vague and the absence of clear and strong categorization caused overlapping in construct categorization in alignment studies [28]. Based on the gap identified, further research is necessary to construct categorization that is clear and strong in business-IT alignment study. Previous studies on alignment basically concentrated on IT alignment from the perspectives of Strategic Information System Planning (SISP) success in the context of purely profit organizations or business entities. Alignment is a concern not only amongst commercial organisations but universities which have invested equally heavily in IT. Despite large investment in IT for the purpose of teaching and learning, and effectiveness of administrative processes, only a small number of researchers studied the alignment in the institutions of higher learning, i.e. [19], [29-30], [24] and [31].

Earlier studies in business-IT alignment in institutions of higher learning seemed to focus on strategic and structural dimension of business-IT alignment. This limitation could be due to the past researchers' dependency on the assumption that both universities and business organizations share similar organizational structure. According to Albrecht et al., such assumption is not true since universities are extraordinarily complex. Universities operation is based on two different operation principles, i.e. structural and philosophical. Structural principle is practiced in the administration involving physical infrastructure, human resource and finance. Philosophical principle is used at the faculty level, which is responsible for the content and quality of program/curriculum. The idiosyncrasy of university's organizational structure is more apparent with the conflict between university administration and faculty administration. University administration often compromise in order to achieve organizational integration, whereas faculty administration never compromise in its pursuit of academic excellence and innovation. Due to this, the challenge for university's business- IT alignment should not only run parallel with organizational planning, investment, importance, and action that was created by the university's highest management council, but also run parallel with different groups of faculties that always change their aims in the pursuit of academic excellence and innovation.

\section{LITERATURE REVIEW}

Research in alignment has garner attention despite decades of research due to the many practical challenges it presents. Research on strategic alignment seems to focus on the state or outcome of alignment with some researchers examining alignment using broad, holistic perspective [18]. Several researchers developed models integrating the business and IT domains [7]. In the past decade, researchers further developed theoritical model on the performance impacts of alignment and its antecedent factors influencing alignment [24]. Many of the models tested showed alignment as seen to be significantly correlated with perceived business/organizational performance both in small firms [32-33] and large organizations [16]. Other studies have failed to indicate a relationship between IT spending and business profitability [34]. This indicates that firm performance is likely to be determined by the interaction of various factors [16]. Nevertheless, there has been little theory based empirical research on the relative importance of the factors affecting alignment in higher education institutions. Our literature review aims to provide more insights on business-IT alignment dimensions and further discuss and analyze antecedent factors affecting alignment followed by discussing prior studies on alignment in universities.

\section{A. Business-IT Alignment Dimensions}

Studies towards the development of a new business-IT alignment model or extending the existing model has stretched business-IT alignment concept across many dimensions [35]. This expansion has motivated past researchers to categorize alignment's construct in order to clarify the models they developed. Strategic Alignment Model by Henderson and Venkatraman [7] shows three stages where alignment could be applied, i.e. strategic stage (involving business strategy and IT strategy), operational stage (involving business infrastructure and IT infrastructure), and cross-domain stage (linking strategic stage and operational stage). Melville, Kraemer and Gurbaxani's [26] model explains business-IT alignment as integration between IT human resource, IT technology resource and complementary organizational resource [21]. Hevner et al. [27] discusses business-IT alignment from the environmental perspective which includes human, organization and technology. They emphasized the integration between the three environmental elements should be well managed to develop efficient and effective information systems that support business needs.

The result of scrutinizing the different models discussed above showed that alignment concept definition was based on many categories of construct which are vague and always overlap. The absence of clear and strong categorization caused overlapping in construct categorization in business-IT 
alignment [28] as the construct categorization depended on the researchers' perspective. Therefore it is necessary to have construct categorization that is clear and strong in business-IT alignment study. Chan and Reich [35] put forward construct categorization based on four different dimensions of businessIT alignment i.e. strategic dimension, structural dimension, social dimension and cultural dimension. Strategic dimension refers to formal planning which involves business strategy and IT strategy that complement each other. Structural dimension refers to the integration of business and IT infrastructure. Social dimension refers to situations where business executives and IT executives understand each other as well as are committed in achieving aims, objectives and business and IT plans. Cultural dimension refers to the integration of culture between business and IT. Reich and Benbasat [21] proved that business-IT alignment is the integration between strategic dimension, structural dimension, social dimension and cultural dimension. These four dimensions will be used as categorization construct in this study. Construct categorization using the stated dimensions make it possible a grid that enables the strong and weak construct in the business-IT alignment to be identified. Indirectly, the relationship between the antecedent factors that influence each business-IT alignment can be shown more clearly. Construct categorization can also identify gaps in business-IT alignment research that can be used in future studies.

\section{B. Business-IT Alignment Antecedent Factors}

IT strategy cannot be aligned with business strategy if organizations do not have formal planning processes and business strategies are not clear [36-38]. A study on IT planning in public organisation showed that strategic planning process contributed towards knowledge sharing which then influenced alignment [39]. Without strategic business planning and IT, it is impossible to achieve business-IT alignment [20]. On the other hand, a number of past studies showed that the absence of shared knowledge domain would hinder businessIT alignment [19] and [37]. The structure of small and medium firms is based more on function, and the central structure is used for management. Central management limits the need for outside mechanism which in the end, hinders alignment. On the other hand, big firms divide organization into divisions and use decentralized management structure. Decentralized management for each division requires outside mechanism to integrate activities of each division in order to achieve organizational aim [40]. In addition, big firms possess resources that can be invested to identify and implement technologies that support business strategies [21].

Most of the business-IT alignment factors indicated by Luftman [41] referred to the necessary management resources that enhance IT values in organization [41]. These management resources include management support towards IT initiative and IT leadership in business. Alignment improved when top management encouraged business involvement in IT planning and the opposite happened if discouraged [42- 43]. The emergence of a new breed of IT managers can be seen to actively move beyond the fire fighting mode of behavior, regaining control and leading their organization to support their organization's evolving corporate strategies [58]. Business-IT alignment is also influenced by factors outside the organization's control. Changes and turbulence in the organization's environment, potential development impact, and choices of existing strategies increased the need for information processing and information system [44-45]. In the academic environment, indicators towards environmental instability, such as changes in courses' demand, competitors' innovation and government policy have strong influence on alignment [23]. Since IT enables organizations to acquire, process, store information in an uncertain environment, management will depend more on IT, hence increasing investment in IT. As a result, management will pay more attention on aligning IT and business strategies [46].

Table 1 shows eight studies on business-IT alignment antecedent factors that have been identified to become the main reference. Based on Chan and Reich [35] construct categorization which is based on four different dimensions of business-IT alignment, it shows that only Motjolopane [28] and Albrecht [29] studied alignment encompassing the four dimensions. The study by Sabherwal \& Kirs [18] did not cover factors that influence the strategic dimension while Hisham \& Daud [31] exclude the cultural dimension. Studies on alignment in higher institutions of learning seem to focus more on strategic dimension followed by social and structure and least on culture. The emphasis on strategic indicated that the strategic dimension is a strong determinant to business-IT alignment. However, the factors in the other dimensions are equally important to achieve success in alignment that contributes to organizational performance. The factors discovered from prior research on alignment can be enriched by additional empirical insight into other possible factors affecting alignment specifically, in this research context, to universities in Malaysia.

\section{Business IT Alignment and Organisational Performance}

The implication of alignment on business performance and IT had been shown through a number of past studies [16], [46], [47] and [23]. Business-IT alignment increased organization profit, more than only using industry and strategy [48], [49], [16] and [22]. Sabherwal \& Chan's [18] study showed a significant relationship between business-IT alignment and organizations performance. On the other hand, the relationship is complex and dependent on business strategy. Yetton [50] explained that the separation of business from IT caused failure in the organization to manage and extract the value of IT. The findings of [50] showed that when there is separation of business from IT organizational performance would drop. As a whole, the results of past studies showed organizations that achieve business-IT alignment had better performance than those that failed to achieve business-IT alignment. Business-IT alignment that used IT was more focused and strategic, resulting in increased organizational performance [24].

\section{Business-IT Alignment At Institutions of Higher Learning}

Business-IT alignment studies at institutions of higher learning were conducted across continents since the last decade. The aspects that were studied discussed the relationship of the factors that influenced alignment and on 
the relationship between alignment and organizational success [24] and factors that influenced alignment and their effect on the success of strategic information system planning [31]. Issues on the effectiveness and success in SISP has raised the question whether or not public universities have taken the right approach or track from the effectiveness in achieving

[2], [52-53] and [31]. To address this issue, Hisham and Daud [31] examined the causal relationship between strategic alignment and SISP in the context of Malaysian public universities. Their research identified that the significant strategic alignment especially when universities have invested heavily in IT for teaching, education and administration [51], factors contributing to alignment are governance competency, communication, sharing, scope, architecture and skills. However, the factors studied by Hisham and Daud [31] were based on factors identified in business organization alignment in the West.

TABLE I. FACTORS INFLUENCING ALIGNEMENT BASED ON DIMENSIONS

\begin{tabular}{|c|c|c|c|c|c|c|c|c|}
\hline Dimension/Factor & $\begin{array}{l}\text { Sabher } \\
\text { wal \& } \\
\text { Kirs } \\
\text { (1994) }\end{array}$ & $\begin{array}{l}\text { Reich } \\
\text { \&Benb } \\
\text { asat } \\
(1996)\end{array}$ & $\begin{array}{l}\text { Luftm } \\
\text { an, } \\
\text { Papp } \\
\text { \& } \\
\text { Brier } \\
\text { (1999) }\end{array}$ & $\begin{array}{l}\text { Hussin } \\
\text {, King } \\
\text { \&Crag } \\
\text { g } \\
\text { (2002) }\end{array}$ & $\begin{array}{l}\text { Motjol } \\
\text { opane } \\
\& \\
\text { Brown } \\
(2004)\end{array}$ & $\begin{array}{l}\text { Albrec } \\
\text { ht et } \\
\text { al. } \\
(2004)\end{array}$ & $\begin{array}{l}\text { Chan, } \\
\text { Sabherw } \\
\text { al \& } \\
\text { Thatcher } \\
\text { (2006) }\end{array}$ & $\begin{array}{l}\text { Hisham } \\
\text { Md } \\
\text { Basir \& } \\
\text { Mohd } \\
\text { Daud } \\
\text { Norzaidi } \\
\text { (2009) }\end{array}$ \\
\hline \multicolumn{9}{|l|}{ Strategic } \\
\hline Shared business and IT & & & $\sqrt{ }$ & & & & & $\sqrt{ }$ \\
\hline Rasional adaptation in SISP & & & & & $\sqrt{ }$ & & & \\
\hline Effective planning & & & & & & $\sqrt{ }$ & & \\
\hline Strategic planning process & & & & & & & $\sqrt{ }$ & \\
\hline Skill in alignment & & & & & & & & $\sqrt{ }$ \\
\hline \multicolumn{9}{|l|}{ Structure } \\
\hline IT implementation process & & & & & $\sqrt{ }$ & & & \\
\hline Governance & & & & & & $\sqrt{ }$ & & $\sqrt{ }$ \\
\hline IT measurement process & & & & & & $\sqrt{ }$ & & \\
\hline Organisational size & & & & & & & $\sqrt{ }$ & \\
\hline Competency measurement & & & & & & & & $\sqrt{ }$ \\
\hline Scope and architecture & & & & & & & & $\sqrt{ }$ \\
\hline \multicolumn{9}{|l|}{ Social } \\
\hline Environmental turbulence & $\sqrt{ }$ & & & & $\sqrt{ }$ & & $\sqrt{ }$ & \\
\hline IT track record/success & & $\sqrt{ }$ & & & & & $\sqrt{ }$ & \\
\hline $\begin{array}{l}\text { Communication between business and } \\
\text { IT executives }\end{array}$ & & $\sqrt{ }$ & & & & & & \\
\hline IT management resource & & & & & $\sqrt{ }$ & & & \\
\hline Leadership involvement & & & & & & $\sqrt{ }$ & & \\
\hline
\end{tabular}




\section{CATEGORIZATION OF FACTORS AFFECTING ALIGNMENT BASED ON DIMENSIONS}

From the literature review, eight studies on business-IT alignment antecedent factors have been identified to become the main reference. All the eight studies involved examined the influence of antecedent factors on business-IT alignment, covering business organizations and institutions of higher learning. These studies have been chosen based on their comprehensive research and directly related with the study being carried out. The types of organizations selected that are not restricted to institutions of higher learning will give a wider perspective on business-IT alignment antecedent factors.

Table 1 shows factors that had been identified by past researchers that influenced the four alignment dimensions. Antecedent alignment factors are tabulated according to business-IT alignment dimensions, with some factors having the same meaning. Correction was carried out on those factors to eliminate overlapping.

\section{RESEARCH MODEL}

Research model shown in figure 1 is based on the theoretical lens as clarified in the literature review. The constructs and variables in the research model are as follows:

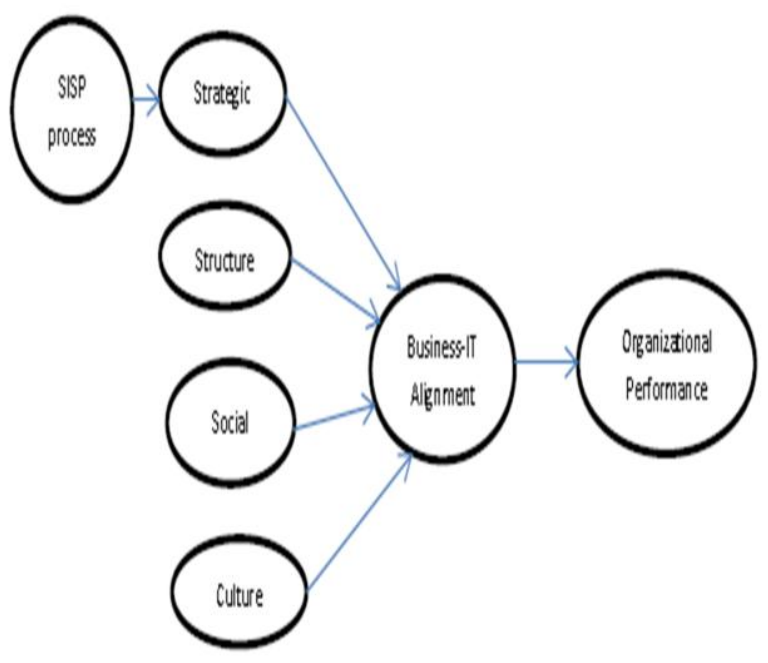

Fig. 1 Research model for Business -IT alignment

- Strategic dimension is defined as a situation where formal planning involves business strategy and IT strategy that complement each other. Factors identified to have potential to influence strategic dimension alignment are sharing of domain knowledge and business-IT planning integration. In this research, as advocated by Chan, Saberwal and Thatcher [24], we are extending the research alignment stream by engaging our quantitative study that links features of strategic planning processes to shared knowledge and IS alignment because of the strong relationships among these processes and factors.
- Structure dimension is defined as a situation where business and IT infrastructure is integrated. Factors identified to have potential to influence structure dimension alignment are IT sophistication, IT expertise, IT implementation process, governance, IT measurement and size of organization.

- Social dimension is defined as a situation where business executives and IT executives understand each other as well as committed to achieve business and IT's aims, objectives and plans. Factors identified to have potential to influence social dimension alignment are effective business-IT executive communication, IT achievement record and uncertainty of environment.

- Cultural dimension is defined as a situation where cultural integration exists between business and IT. Factors identified to have potential to influence cultural dimension alignment are management commitment towards IT and IT leadership.

Factors in each of the alignment dimension above are independent variables whereas organizational performance is the dependent variable in this study. Though there are many methods to measure organizational performance, this study will use subjective measurement rather than objective measurement because the former gives organizational performance a wider concept. This study will use the instrument developed by Khandwalla [54] and four statements will be used to evaluate organizations' performances compared to their competitors: Total number of registered post-graduate students, post-graduate students-faculty ratio, the number of students with first class degree, image of organization.

\section{CONCLUSION}

Studies on business-IT alignment have developed models which integrate business domain and IT. Researchers have made improvement to the alignment model by introducing the performance impact and antecedent factors which influenced alignment. Past research findings revealed that successful alignment focuses on managing specific alignment dimension by investigating factors that encourage particular dimension. However, the findings revealed the absence of clear and strong categorization that had caused overlapping in construct categorization which resulted in confusion in clarifying the business-IT alignment concept. This research has studied four dimensions: strategic, structure, social and culture influencing alignment that can be used for categorization of constructs. Construct categorization using the four dimensions make it possible a grid that enables the strong and weak construct in the business-IT alignment to be identified. The categorization of construct is important to support the formation of a theoretical business-IT alignment model that has impact on organizational performance. The validated model can help analyse business-IT alignment relationship with Malaysian public universities so that these relationships and best practices can be better understood to help universities' achieve alignment. The model could also serve as compass to navigate Malaysian public universities' IT investments in line with 
National Key Economic Activities (NKEA) to make Malaysia a regional hub for higher education.

\section{REFERENCES}

[1] M. J. Earl, Corporate Information Systems Management. Homewood: Richard D. Irwin Inc., 1983.

[2] M. J. Earl, "Experiences in Strategic Information Systems Planning," MIS Quarterly, vol. 17, pp. 1-24, 1993.

[3] Robson, W. Strategic Management and Information Systems: An Integrated Approach, London: Pitman Publishing, 1994.

[4] J. King, "Re-engineering Focus Slips". Computerworld vol. March 13, pp. 6, 1995.

[5] Papp, R., and Luftman, J. "Business and IT Strategic Alignment: New Perspectives and Assessments," In Proceedings of the Association for Information Systems, Inaugural Americas Conference on Information Systems, 1995 .

[6] Pittsburgh, PA, August 25-27, 1995.O. Velcu, "Strategic alignment of ERP implementation stages: An empirical investigation," Information \& Management, vol. 47, pp. 158-166, 2010.

[7] J. C. Henderson and H. Venkatraman, "Strategic alignment: Leveraging information technology for transforming organizations," IBM Systems Journal, vol. 38, pp. 472-484, 1999.

[8] R. Papp, "Alignment of Business and Information Technology Strategy: How and Why?" Information Management 11, vol.3(/4), pp. 6-11, 1998.

[9] J. Henderson, and N. Venkatraman, "Strategic Alignment: A model For Organizational Transformation Via Information Technology", Working Paper 3223-90, Cambridge, MA: Sloan School of Management, Massachusetts Institute of Technology, 1990.

[10] J. Henderson, and N. Venkatraman, "Aligning Business and IT Strategies", J.N. Luftman (ed.) Competing in the Information Age, New York:Oxford University Press, 1996.

[11] J. N. Luftman, et al., "Transforming the enterprise: The alignment of business and information technology strategies," IBM Systems Journal, vol. 32, pp. 198-221, 1993.

[12] J. Luftman, "Competing in the Information Age: Practical Applications of the Strategic Alignment. Model", New York: Oxford University Press, 1996.

[13] L. Goff, "You Say Tomayto, I Say Tomahto", Computerworld, vol. Nov. 1, pp. 129, 1993.

[14] S. Liebs, "We're All In This Together", Information Week, vol. October 26, pp.8, 1992

[15] R. T. Watson and J. C. Brancheau, "Key issues in information systems management: An international perspective," Information \& Management, vol. 20, pp. 213-223, 1991.

[16] Y.E.Chan , S.L. Huff, D.W. Barclay, D.G. Copeland, "Business Strategic Orientation, Information Systems Strategic Orientation, and Strategic Alignment", Information Systems Research vol. 8(2), pp. 125 150, 1997.

[17] P.P. Tallon, “The Alignment Paradox”, CIO Insight, vol. 1(47), 2003.

[18] R. Sabherwal and Y. E. Chan, "Alignment Between Business and IS Strategies: A Study of Prospectors, Analyzers, and Defenders," Info. Sys. Research, vol. 12, pp. 11-33, 2001.

[19] R. Sabherwal and P. Kirs, "The Alignment between Organizational Critical Success Factors and Information Technology Capability in Academic Institutions*," Decision Sciences, vol. 25, pp. 301-330, 1994.

[20] J. Luftman, et al., "Enablers and inhibitors of business-IT alignment," Commun. AIS, vol. 1, p. 1, 1999.

[21] B. H. Reich and I. Benbasat, "Factors that influence the social dimension of alignment between business and information technology objectives," MIS Q., vol. 24, pp. 81-113, 2000.

[22] P. Cragg, et al., "IT alignment and firm performance in small manufacturing firms," The Journal of Strategic Information Systems, vol. 11, pp. 109-132, 2002.
[23] G. S. Kearns and A. L. Lederer, "A Resource-Based View of Strategic IT Alignment: How Knowledge Sharing Creates Competitive Advantage," Decision Sciences, vol. 34, pp. 1-29, 2003.

[24] Y.E. Chan, R. Sabherwal, \& J.B. Thatcher, "Antecedents and Outcomes of Strategic IS Alignment: An Empirical Investigation", IEEE Transactions On Engineering Management vol. 53(1), pp. 27-47, 2006.

[25] J.W. Ross, C.M. Beath, D.L. Goodhue, "Develop Long-Term Competitiveness through IT Assets", Sloan Management Review vol. 38(1) pp. $31-42,1996$.

[26] N. Melville, et al., "Review: information technology and organizational performance: an integrative model of it business value," MIS Q., vol. 28, pp. 283-322, 2004.

[27] A. R. Hevner, et al., "Design science in information systems research," MIS Q., vol. 28, pp. 75-105, 2004.

[28] S. Frank, "Reconsidering the Dimensions of Business-IT Alignment," pp. 5053-5061, 2012.

[29] I. Motjolopane and I. Brown, "Strategic business-IT alignment, and factors of influence: a case study in a public tertiary education institution," presented at the Proceedings of the 2004 annual research conference of the South African institute of computer scientists and information technologists on IT research in developing countries, Stellenbosch, Western Cape, South Africa, 2004.

[30] B. Albrecht, , B. Bender, R.N. Katz, J.A. Pirani, G. Salaway, T.D. Sitko, J. Voloudakis, "Information Technology Alignment in Higher Education”, EDUCAUSE Center for Applied Research, 2004.

[31] H.M. Basir, M.N. Daud, "The Effect of Strategic Alignment on Strategic Information System Planning (SISP) Success: An Exploratory Study in Public Universities in Malaysia", International Journal of Scientific Research in Education, vol. 2(2), pp. 76 - 87, 2009.

[32] Dvir et al (2003)

[33] C. P. Armstrong and V. Sambamurthy, "Information Technology Assimilation in Firms: the Influence of Senior Leadership and it Infrastructures," Info. Sys. Research, vol. 10, pp. 304-327, 1999.

[34] Hitt and Brynjolfsson (1996)

[35] Y.E. Chan, B.H. Reich, "IT Alignment: What have we learned?" Journal of Information Technology, vol. 22(4), pp. 297 - 315, 2007.

[36] M.R. Vitale, B. Ives, C.M. Beath, "Linking Information Technology and Corporate Strategy: An organizational view", Proceedings of International Conference of Information Systems, pp. 256 - 276, 1986.

[37] E. T. G. Wang and J. C. F. Tai, "Factors affecting information systems planning effectiveness: organizational contexts and planning systems dimensions," Information \& Management, vol. 40, pp. 287-303, 2003.

[38] M. Alsouri, \& J. Salim, 'Strategic Information System Planning: Review", International Review on Computers and Software vol. 6(1), pp.11-17, 2009.

[39] D. Sledgianowski, J. Luftman, "IT-Business Strategic Alignment Maturity: A case study", Journal of Cases on Information Technology, vol.7(2), pp. $102-120,2005$.

[40] J. Cohen, "A Cross-National Comparison of Determinants and Consequences of IS-Business Social Alignment", Proceedings of the 4th Annual Global Information Technology Management World Conference, pp. 273-276, 2003.

[41] J.N Luftman, "Assessing Business-It Alignment Maturity", Communications of AIS vol. 4, pp. 1-51, 2000.

[42] A. L. Lederer and A. L. Mendelow, "Coordination of information systems plans with business plans," J. Manage. Inf. Syst., vol. 6, pp. 519, 1989.

[43] L. L. Martins and A. Kambil, "Looking Back and Thinking Ahead Effects of Prior Success on Managers' Interpretations of New Information Technologies," The Academy of Management Journal, vol. 42, pp. 652-661, 1999.

[44] R. L. Daft and R. H. Lengel, "Organizational Information Requirements, Media Richness and Structural Design," Management Science, vol. 32, pp. 554-571, 1986.

[45] Y.P. Gupta, J. Karimi, T.M. Somers, "Alignment of a Firm's Competitive Strategy and Information Technology Management 
Sophistication: The missing link", IEEE Transactions on Engineering Management vol. 44(4), pp. 399-413, 1997.

[46] J. de Leed, J.C. Looise, B. Alders, "Innovation, Improvement and Operations: An exploration of the management of alignment", International Journal of Technology Management vol. 23(4), pp. $353-$ $368,2002$.

[47] Z. Irani, "Information systems evaluation: navigating through the problem domain," Inf. Manage., vol. 40, pp. 11-24, 2002.

[48] S. W. Floyd and B. Wooldridge, "Path analysis of the relationship between competitive strategy, information technology, and financial performance," J. Manage. Inf. Syst., vol. 7, pp. 47-64, 1990.

[49] T. C. Powell, "Organizational alignment as competitive advantage," Strategic Management Journal, vol. 13, pp. 119-134, 1992.

[50] P. Yetton, "False prophecies, successful practice and future directions in IT management," presented at the Proceedings of the IFIP TC8 Open Conference on Business Process Re-engineering: Information Systems Opportunities and Challenges, 1994.

[51] Doherty, N.F., Marples, C.G., Suhaimi, A., " The relative success of alternative approaches to Strategic Information Systems Planning: an empirical analysis," Journal of Strategic Information Systems, vol. 8. pp. 263-283, 1999.
[52] Gonzalez, R., Gasco, J., Llopis, J., "Information systems outsourcing risk; a study of large firms, industrial management and data systems." Vol. 105, pp. 45-62

[53] Newkirk, H.E., "Environmental Uncertainty in Strategic Information Systems Planning Comprehensiveness.” PhD. Dissertation, College of Business and Economics, University of Kentucky, Kexington, Kentucky.

[54] P.N. Khandwalla, “The Design of Organisation", New York: Harcourt Brace Jovanovich, 1977

[55] Spremic, M. Methodologies for Evaluating IT Business Value Management. Proceedings of the 10th WSEAS International Conference on Automation \& Information, Prague, pp.227-232, 2009.

[56] Coso Enterprise Risk management Integrated framework. September 2004, www.coso.org7publications.htm accessed August 2013.

[57] TTGI and Price Waterhouse Cooper. IT Governance Global Status Report, IT Governance Institute, Rolling Meadows Illinois, SAD 2006.

[58] Pannian, Z. The Framework to Realign IT with business: A Role of Data Protection. Proceedings of the $5^{\text {th }}$ WSEAS Int. Conference on Applied Informatics and coomunications, Malta, September, 15-17,227-232, 2005 .

\section{Creative Commons Attribution License 4.0 (Attribution 4.0 International, CC BY 4.0)}

This article is published under the terms of the Creative Commons Attribution License 4.0

https://creativecommons.org/licenses/by/4.0/deed.en_US 